\title{
Um convite para um começo de conversa sobre a graduação em Psicologia: pensando uma versão da Psicologia do Desenvolvimento pela TAR
}

\section{An invitation to the beginning of a conversation about graduation in Psychology: thinking an ANT version for Developmental Psychology}

\section{Una invitación para un comienzo de conversación sobre grado en Psicología: pensando una versión de la Psicología del Desarrollo por la TAR}

\section{Luciana Loyola Madeira Soares*}

Universidade do Estado do Rio de Janeiro - UERJ, Rio de Janeiro, Rio de Janeiro, Brasil

\begin{abstract}
RESUMO
Apresentamos uma reflexão sobre as práticas na graduação em Psicologia, partindo de uma breve revisão histórica e crítica da Psicologia do Desenvolvimento. Caminhamos pelas formulações iluministas da Ciência Moderna que deram sustentação ao projeto racionalista e individualista enredado na lógica do liberalismo econômico e que colocou o conhecimento voltado para a técnica e leis de mercado no centro do projeto de formação universitária. Apontamos que tais formulações contribuíram para o estabelecimento de uma apolítica noção de desenvolvimento humano, assim como para as práticas de ensino e aprendizagem na referida disciplina e na graduação como um todo. Propomos uma perspectiva ao estudo do desenvolvimento humano que se vincule à presença do outro: a problematização através de práticas éticas em sala de aula na graduação em Psicologia. Apontaremos a Teoria Ator-Rede (TAR) como suporte teórico para uma atitude investigativa para o docente, por fornecer condições para pensarmos o desenvolvimento humano a partir das experiências tecidas em redes e conexões, onde os afetos e a criatividade têm vez, e não só o tecnicismo, a competição, a adaptabilidade e o adestramento.

Palavras-chave: psicologia do desenvolvimento, ciência moderna, TAR.
\end{abstract}

\section{ABSTRACT}

We present our thoughts about graduation in Psychology by a critical and historical review of the Developmental Psychology. Since the illuminist view in Modern Science entanglement with the logic of the economic liberalism supported a rationalistic and individualistic project for the human being, we intend to discuss how these formulations have contributed for an idea of human development related to the wealth of the countries. We point out that all those ideas interfered in the graduation in psychology as it gave it an apolitical face. So, we intend to raise questions about the importance of the 
other's presence since classroom, in order to set up an ethical attitude. We propose the Actor-Network Theory (ANT) as a way to the studies of the Human development with a political face, in which the presence of the other means much more, by connecting humans and non humans, technology, competition, feelings and creativity.

Keywords: developmental psychology, modern science, ANT.

\begin{abstract}
RESUMEN
Presentamos una reflexión sobre las prácticas de estudio de grado en Psicología partiendo por una breve revisión histórica y crítica de la Psicología del Desarrollo. Caminamos por las formulaciones iluministas de la Ciencia Moderna que dieron sustento al proyecto racionalista e individualista vinculado a la lógica del liberalismo económico, que orientó el conocimiento y el centro del proyecto de formación universitaria hacia las técnicas y leyes del mercado. Señalamos que tales formulaciones contribuyeron al establecimiento de una noción apolítica del desarrollo humano, así como de las prácticas de enseñanza y aprendizaje en la disciplina referida. Planteamos una perspectiva al estudio del desarrollo humano que se vincule a la presencia del otro: la problematización a través de prácticas éticas en la sala de clases durante el estudio de grado en Psicología. Proponemos la Teoría del Actor-Red (TAR) como soporte teórico para una actitud investigativa del docente por entregar condiciones para pensar el desarrollo humano a partir de las experiencias tejidas en redes y conexiones, donde los afectos y la creatividad tienen su momento, y no solo el tecnicismo, la competencia, la adaptabilidad y el adiestramiento.
\end{abstract}

Palabras clave: psicología del desarrollo, ciencia moderna, TAR.

\title{
1 Introdução
}

A experiência de lecionar a disciplina Psicologia do Desenvolvimento na graduação em Psicologia nos tem trazido muitas inquietações. Observamos que esta disciplina figura na grade curricular impregnada de descrições e expectativas relacionadas a um desenrolar de acontecimentos pautados numa linha cronológica que, ao cumprir um encadeamento sucessivo e ordenado através de determinações, escalas, padrões e classificações, aponta para um sujeito idealizado e individualizado, portanto, em sintonia com a norma burguesa/capitalista de produtividade, saúde, sucesso e felicidade.

Pretendemos propor neste texto um início de discussão acerca das práticas de ensinar e aprender na disciplina Psicologia do Desenvolvimento que figura na grade curricular da graduação em Psicologia, e que, a partir de suas ementas, focalizam predominantemente o aspecto biológico dos processos do ciclo vital humano, apontando o 'social' como interferência externa ao ser em desenvolvimento, fazendo-a constituir-se numa disciplina apolítica, portanto. Conservando um olhar dicotômico, generalista, linear, excludente, causalista e determinista aos percursos existenciais, tais estudos mantêm uma cronologia a ser passivamente cumprida, que vai da concepção à morte dos humanos, em detrimento das 
peculiaridades relacionais que produzem histórias de vida singulares. Da mesma maneira, as práticas docente e discente ficam engessadas, se considerarmos esta premissa cronológica para pautar a referida disciplina, como encontramos em Soares (2011):

"Entendemos a graduação em Psicologia como necessariamente tecida por fios de sustentação nas relações entre professores e alunos e nas dos alunos entre si. Isso efetivamente é uma compreensão que vai muito além do mero somatório entre conhecimentos teóricos e o acesso a ferramentas de cunho operacional e tecnicista para habilitar alguém que se candidata ao exercício da profissão de psicólogo. Acreditamos que a formação universitária de psicólogos não possa ser regulada pelos ditames de um sistema tecnicista e mercadológico, impondo competitividade e isolamento no interior do alunado e pressa e eficácia no fornecimento e na aquisição de conhecimentos ao par professor/aluno." (p. 78)

Fundamentados na Teoria Ator-Rede (TAR), pretendemos problematizar o desenvolvimento numa perspectiva processual e relacional, levando em conta o sujeito como ator numa rede de mútuas afetações que perpassam seu ciclo vital de maneira singular, produzindo histórias que se caracterizam mais pelos fazeres que engendram processos existenciais marcados por contextos sóciohistóricos específicos. Aqui, ao elegermos a graduação em Psicologia como cenário para a problematização das práticas em Psicologia do Desenvolvimento, propomos que o foco desta disciplina não fique restrito a ementas que propõem repetir marcos cronológicos, a fim de estabelecer padrões para definir resultados e, sim, seguir os processos que tecem subjetividades, nas quais os sujeitos são criativamente ativos e conectados em rede com humanos e nãohumanos. Ao Interessarmo-nos pelos desvios que produzem 0 surpreendente, através de narrativas que criam as diferenças e ampliam conexões, podemos possibilitar que emirja o criativo e, não - repetitivo na própria rede engendrada em sala de aula, transformando a experiência acadêmica num fazer ético, portanto. Pleiteamos que o estudo a partir da disciplina Psicologia do Desenvolvimento privilegie o fazer com, em vez do falar sobre algo já dado, tido como conhecimento universal.

\section{Na sala de aula na graduação em Psicologia - uma interlocução possível entre o moderno e o contemporâneo?}

Ao nos determos a pensar sobre 'Desenvolvimento' lembramos que a palavra nos remete a envoltura, envolver, envolvimento, volver, dar 
vez a, criar - termos que nos remetem a crescer, soltar-se, lançar-se, voltar. De qualquer modo, é clara a ligação com algum tipo de movimento; a direção do movimento é que não está definida, se pensarmos em sair da trajetória determinista presente nas ementas, nos textos e práticas ainda utilizados nas práticas docentes nesta disciplina.

$\mathrm{Na}$ graduação em Psicologia professores e alunos herdam alguns problemas; primeiramente: fazer a interlocução entre as diferentes epistemologias que fazem demarcações teóricas e não propiciam o diálogo, a ampliação das conexões, das práticas e, portanto, a criação de novas versões para além das restrições rigorosamente definidas. As informações são da ordem do conhecimento 'fechado' em si mesmo, pronto, a ser oferecido pelo professor e a ser consumido pelo estudante; cabe ao futuro psicólogo a tarefa de adquirir conteúdos cujo percurso de engendramento por seus atores não faz parte do que deverá aprender. É frequente ouvirmos dos alunos o relato de que as disciplinas parecem não fazer sentido entre si, como se a graduação fosse um colcha de retalhos. Esse paradigma em subjetivação figura inclusive no empenho individualizado de ensinar e de adquirir o ofício de psicólogo pelo domínio do tecnicismo: o oferecimento de ferramentas básicas para o exercício futuro da profissão, indicando afastamento da construção do papel de psicólogo pela formulação do desenvolvimento do/no coletivo. Ética e técnica em conflito desde a universidade.

Recorremos à TAR, que propõe que as diferenças são abraçadas como nuances que colorem as possibilidades de construção de diálogos entre a variedade dos saberes psicológicos - seguimos as conexões. Isso favorece o tom de 'múltipla' à Psicologia: estudando sujeitos encarnados, mundos que coexistem num dado momento. Como as realidades são engendradas, ela retira-se de um lugar conceitual para uma condição de materialidade.

Outro problema da modernidade herdado pelos professores e pelos estudantes de Psicologia é o 'sujeito da interioridade', em que homem e sociedade são separados e estudados sob enfoques diferentes. A mesma modernidade que criou a interioridade criou o segredo, de acordo com Despret (2011b); e, o psicólogo tornou-se o profissional que maneja o segredo. O aluno aprende a lidar com (e manter) aquilo que separa um indivíduo do outro, o que é escondido, não revelado. Fundamentando-nos na TAR voltamo-nos para como os modos de existência nos subjetivam, o que equivale a afirmar um fazer pelo primado da perspectiva relacional, importando-nos com o que é produzido em rede e a rede que é produzida - o sujeito é considerado um ponto, uma conexão da rede. Quadros (2011) aponta uma contribuição da TAR às práticas em Psicologia: "... os acontecimentos são movimentos onde objetos e pessoas estão em conexão formando elementos híbridos com uma certa 
indissociabilidade. Portanto, a ênfase está nas conexões, articulações, alianças, constituindo redes que produzem formas, relações, deslocamentos impermanentes." (p.59). Em Moraes (2003):

"A noção de rede permite reativar o campo problemático constitutivo da Psicologia: seus impasses para se constituir como uma ciência que, pela proposição de leis gerais, funcione como justificativa para o problema do erro, seja na cognição, seja no domínio da prática. ... Considerar a Psicologia como uma ciência em rede, uma ciência em ação, significa pensar um novo estilo de ciência para a Psicologia...".

Em seu mais recente trabalho, Castro (2013) indica que o pesquisador em Psicologia do Desenvolvimento está comprometido afetivamente, sócio-historicamente e teoricamente ao focalizar que a temporalidade, a espacialidade, memórias, as mudanças, o diferir e o transformar-se não se opõem, não são rigidamente delimitáveis, nem mutuamente excludentes, e sim, participam do engendramento do imponderável percurso da existência humana: "A convivência de tempos heterogêneos e distintos, o que passou e o que ficou fixo e imóvel, permite uma abordagem muito mais nuançada das experiencias humanas, envoltas na memória cujas possibilidades de ir e vir na linha do tempo asseguram a percepção do contraditório e do imprevisível das ações e dos sentimentos humanos." (p.33). E, mais adiante:

“... o enlace afetivo que cada pesquisador faz com a infância parece comprometê-lo a caminhos teóricos variados, alimentados pela gama de evocações e mobilizações de que a infância é portadora. A abordagem teórica da subjetividade infantil, desafiada pelas condições inusitadas do contemporâneo, ecoa um imaginário espesso de sentidos, dentre os quais se avultam as questões da temporalidade e da espacialidade, do antes e do depois, ... e do que está "entre". (p.34)

Assim, pensamos neste texto como um convite aos professores e aos estudantes a ampliar o olhar incluindo tudo o que implica desenvolver-se. Recorremos a Moraes (2001), ao refletir sobre a Psicologia que inclui os impasses, a incerteza e os riscos, entre o erro e a errância, apontando o nomadismo e a hibridação como caminhos para: "... buscar um estilo de ciência para a psicologia que não seja pautado num modelo tomado de empréstimo de outras ciências, ... redefinir o estatuto do erro como campo de estudos da psicologia". Consideramos desafiador tanto para o aluno quanto para o professor inventar um caminho acadêmico que consista em pesquisar a própria 
prática: o que/quem se desenvolve quanto se estuda o desenvolvimento?

\section{Um pouco do desenvolvimento na/ da Psicologia do Desenvolvimento}

A Psicologia Moderna tem base na subjetividade liberal - foco no indivíduo (Mattos, 2012). Ainda de acordo com a autora: "A mensuração de habilidades, inteligência e comportamentos, com seus resultados aplicados à comparação, regulação e controle de grupos e sociedades, está intimamente relacionada com o estabelecimento de normas a respeito da infância e de seu desenvolvimento." (p.90). As relações no mundo contemporâneo são marcadas pelo predomínio da técnica, da repetição, da normatização pelo saber científico, pela lógica do liberalismo econômico prescrevendo a existência - modo de viver padronizado, organizado por materialismo, competitividade, acúmulo e consumo de bens, pela velocidade - em detrimento da abertura ao que pode ser criado a partir do sensível, dos afetos, do reconhecimento das diferenças nos encontros. Segundo Quadros (2011), a modernidade: "... seria uma pretensão de chegar à essência das "verdades" e, ... à garantia das certezas onde a ciência seria a legisladora dos modos de organização de um mundo factual, estável, regular, apreensível e explicável."

A Psicologia do Desenvolvimento constituiu-se nos pressupostos cientificistas destacando a infância como fase primordial da existência e, colocando a maternagem como fundamental para um desenvolvimento bem sucedido, o que implica literalmente a figura da mãe/mulher como cuidadora principal e individual (Pombo, 2013). Deste modo, a ideia de infância e de feminino associam-se em prol do bem estar da família e da nação, assim como estabelece um recorte apolítico das práticas envolvidas no desenvolvimento humano: como se apenas importasse o par mãe/bebê no processo de socialização.

Observamos que, na própria grade curricular do curso de graduação em Psicologia as ementas e programas da disciplina Psicologia do Desenvolvimento figuram impregnados de descrições e expectativas relacionadas a um desenrolar de acontecimentos pautados numa linha cronológica que, ao cumprir um encadeamento sucessivo e ordenado através de determinações, escalas, padrões e classificações, aponta para um sujeito racional, individual e idealizado, portanto, em sintonia com a norma burguesa/capitalista de produtividade, saúde, sucesso e felicidade. De acordo com Mattos (2012): "A mensuração de habilidades, inteligência e comportamentos, com seus resultados aplicados à comparação, regulação e controle de grupos e sociedades, está intimamente relacionada com o estabelecimento de normas a respeito da infância 
e de seu desenvolvimento." (p.90). Figurando nos períodos iniciais da grade curricular, a ementa da referida disciplina parece indicá-la como ferramenta para dar sustentação a disciplinas que figurarão nos períodos seguintes, como Psicodiagnóstico, Psicologia Escolar, Problemas de Aprendizagem, etc.

Os estudos em Psicologia do Desenvolvimento ainda vigentes na bibliografia indicada para os estudantes de Psicologia quando cursam esta disciplina focalizam predominantemente o aspecto biológico dos processos do ciclo vital humano, apontando o 'social' como interferência externa ao ser em desenvolvimento. Conservando um olhar dicotômico, generalista, linear, excludente, individualista, causalista e determinista aos percursos existenciais, tais estudos mantêm uma cronologia a ser passivamente cumprida, que vai da concepção à morte dos humanos, em detrimento das peculiaridades relacionais que produzem histórias de vida singulares e de um viés político indissociável ao pensarmos nesses processos.

Dando continuidade a esta reflexão, buscamos em alguns textos utilizados na graduação em Psicologia os parâmetros norteadores do pensamento de autores que se dedicaram e que se dedicam ao tema do Desenvolvimento Humano. Os livros que tradicionalmente versam sobre este tema são, em geral, volumosos manuais, organizados por um ou mais autores que se dedicaram ao Desenvolvimento. São livros que, em geral, estão divididos em fases que seguem uma sequência cronológica do ciclo vital; há também divisão por aprendizagem, motricidade, linguagem, controle esfincteriano, identificação sexual, etc. com pouca articulação entre si, como se não compusessem um todo integrado. Mesmo que para estudar bastasse uma soma, que não é o caso, tais aspectos não constituiriam um ser humano. Em várias obras o termo 'desenvolvimento' se embaraça com os termos 'crescimento' e 'evolução', numa perspectiva Darwinista. A Psicologia do Desenvolvimento nasceu com a missão de descrever, explicar, prognosticar e estabelecer a profilaxia de distúrbios da aprendizagem e preparar o 'homem do futuro', dando sustentação a projetos pedagógicos voltados para o adestramento do futuro trabalhador/consumidor. Assim, observamos sua fidelidade aos pressupostos associados à lógica do liberalismo econômico, em que os interesses situam-se em torno da criança enquanto 'riqueza de uma nação'. De acordo com Heckert, Corona, Manzini, Machado e Fardin (2001), "Em tempos neoliberais, preconiza-se a responsabilidade individual na aquisição de habilidades que possam garantir a empregabilidade." (p. 243; itálico dos autores).

O estudo do ciclo vital começou com crianças e foi em direção à velhice; há textos em que esta última fase é curiosamente mencionada como 'declínio', em oposição ao 'início', corroborando a ideia de deixar à margem dos processos sociais e psicológicos os sujeitos economicamente improdutivos. Segundo o olhar crítico de 
Castro (2013), nesta perspectiva o adulto é apontado como o ápice do processo de desenvolver-se.

Muito presentes nas ementas da disciplina Psicologia do Desenvolvimento e nos referidos manuais utilizados na graduação, autores alinhados com Freud, como A. Freud, M. Klein e D. Winnicott, por exemplo, propõem um estudo específico acerca do sujeito do inconsciente, as pulsões, o complexo de Édipo, dentre outros conceitos psicanalíticos e, sua contribuição provém dos casos clínicos que deram vez a hipóteses referentes à origem das neuroses dos adultos - o desenvolvimento pensado à luz da psicopatologia, numa dicotomia entre o ideal de saúde e a doença, e a centralidade da mãe no êxito ou no malogro deste processo.

Piaget dedicou-se a examinar a construção das estruturas de pensamento, o que rendeu a seu trabalho o nome de Construtivismo. Seus estudos privilegiaram o sujeito epistêmico, criando assim a Epistemologia Genética, buscando uma universalidade na construção do conhecimento (La Taille, 1992, p. 109). No entanto, destacamos o fato de que ele restringiu a interferência do 'social' enquanto contribuição ao aspecto cognitivo, pois entendeu que a construção do pensamento é relativamente independente do contexto cultural, social e do momento histórico dos quais os sujeitos fazem parte (La Taille, 1992, p. 112). Tendo como foco a cognição, Piaget indicava sua prevalência inclusive para a construção das noções de moral e ética, apontando que só é ético o sujeito que tenha aprendido a ser cooperativo, o que se alcança mediante o adequado desenvolvimento cognitivo (La Taille, 1992, p. 21). Além disso, Piaget apresentou-nos uma teoria do desenvolvimento que pressupunha uma sucessão de etapas de construção do pensamento, da motricidade e da noção de moral, a serem progressivamente superadas, numa alusão à superação da própria infância.

Vygotsky, em sua abordagem sócio-histórica do desenvolvimento humano, via processualidade e interdependência nos caminhos do desenvolvimento; e, como o seu foco residia na construção das funções psicológicas superiores e da linguagem da criança, os aspectos relacionais - as dimensões social, cultural e histórica - foram fundamentais para seu estudo. Via a cultura como 'palco de negociações' (Oliveira, 1992, p. 80), e a linguagem como mediação simbólica na construção do pensamento, sendo, portanto, a relação com o outro fundamental nesse processo - afetos e cognição são considerados inseparáveis. No entanto, Oliveira (1992) aponta que a articulação do particular com o geral pode ser considerada um problema na obra vygotskiana, já que esse aspecto tende a ganhar dimensão de universalidade em seus trabalhos. Mesmo assim, Vygotsky ainda é um dos autores que mais se aproximam de um olhar relacional e processual ao desenvolvimento humano, com cuja 
contribuição podemos pensar em estabelecer boa interlocução com a TAR.

Carmichael (1964), um dos autores mais clássicos, faz referência ao século XX como o século das crianças, denominação esta que seria proveniente dos estudos em laboratórios de pesquisa norteamericanos. O autor curiosamente nos informa que, historicamente, os estudos do desenvolvimento começaram a partir do final do século XVIII, através de biografias de crianças que se tornaram adultos ilustres relatadas em anotações de diários escritos por seus parentes. Tudo isso foi baseado nos escritos da elite dos letrados da época, refletindo um percurso tendencioso, a ser lido com ressalvas, marcado pela condição socioeconômica dos observados e dos observadores. Já no final do século XIX, estes estudos passam a seguir as normas científicas e são adotados questionários e testagem voltados para investigar, prognosticar e controlar o progresso dos escolares. Assim, as deficiências tornaram-se parâmetros para o desenvolvimento de crianças. O autor cita a importância da obra de Freud, pois a partir deste, a infância ganhou relevo por ser considerada fase determinante na formação das futuras neuroses dos adultos. Percebemos que os autores estabelecem uma relação direta de causalidade entre desenvolvimento e psicopatologia da infância, dicotomia entre o saudável e o patológico, sendo a infância vista como apenas uma etapa a ser pensada como reduto da formação do futuro adulto.

Pikunas (1979), numa obra amplamente utilizada nos anos 80 na graduação em psicologia, valoriza a Psicologia Científica:

"... os psicólogos podem prever progresso continuado para a tríplice meta da ciência do crescimento humano: entendimento, prognóstico e controle da evolução do crescimento e comportamento. Podem aguardar esperançosamente novos discernimentos no intrincado do organismo e da personalidade do ser humano e constatar quais são as incoerências do desenvolvimento e do comportamento, bem como os fatores que os afetam e determinam." (página não numerada na abertura da Parte I)

Mais adiante, afirma que a cultura, a tecnologia, explosão demográfica, conflitos raciais, decisões, desafios e riscos são "problemas externos" (p.4) que agem como complicadores e promovem frustrações ao ser humano em todas as etapas de seu desenvolvimento. $\mathrm{O}$ autor indica o desenvolvimento como fenômeno biologicamente comandado e, que, transcorreria melhor não fossem os eventos, 'obstáculos' por ele elencados como desvios de curso provenientes de 'fora' do sujeito. Há também clara distinção entre o sujeito e o 'social' e evidente valorização do método científico como 
fonte confiável para o estudo a que se propõe, como podemos ver: "As especulações ociosas, as velhas lendas e superstições comadrescas e as máximas de tempos primitivos - muitas das quais perduram até hoje - segundo as constatações, são tristemente deficientes." (p. 4). Assim, histórias de vida tecidas de fantasias, de medos, de traumas foram engendrando as práticas excluídas pelo autor; certamente são narrativas de valor se consideradas como legítima produção de conhecimento situado, que não podem ser omitidas, pois foram compostas por atores em rede, por emoções e compuseram afetações e, portanto, modos de subjetivação.

Gerrig \& Zimbardo (2005) produziram um manual utilizado atualmente como livro-texto de referência em alguns cursos de graduação em Psicologia e, na parte referente à Psicologia do Desenvolvimento indicam que: "A tarefa dos psicólogos do desenvolvimento é descobrir como e por que os organismos mudam com o passar do tempo, documentando e explicando o desenvolvimento." (p.365; grifos dos autores). Embora se trate de obra recente, mantém fidelidade ao pensamento cientificista/positivista/iluminista, biologicamente determinista, causalista e preditivo - é o que podemos chamar de conhecimento não-marcado, não-situado; para todos e, efetivamente, para ninguém.

Papalia, Olds \& Feldman (2006), cujo texto também é utilizado nos dias de hoje em cursos de graduação em Psicologia, apresentam as clássicas divisões por faixas etárias subdivididas em: físico, cognitivo e psicossocial. Definem desenvolvimento: "O campo do desenvolvimento humano constitui-se do estudo científico de como as pessoas mudam, bem como das características que permanecem razoavelmente estáveis durante toda a vida." (p.47; grifo dos autores). Seu enfoque é da ordem do geral para o particular. O sujeito ainda é visto como mais recebedor de influências externas, do que ativo, criativo, em rede de permanentes e mútuas afetações. Professores e alunos na graduação em Psicologia são afetados por esta herança moderna que impregna currículos, textos e práticas.

Stern (1991) produziu um trabalho sobre o desenvolvimento dos primórdios do ciclo vital, cujo fio de construção é um relato fictício da experiência de um bebê narrado ora em primeira pessoa, ora pelo autor. Stern interessa-se pela relação do bebê com seus cuidadores; o autor segue o bebê e vai tecendo hipóteses para suas experiências, que são narradas em minúcias, contendo os tons, os sons e os odores do ambiente e as expressões e emoções vividas em sua relação com os que com ele estão. O autor pensa o geral pelo particular, não estabelecendo leis universalizantes ou verdades absolutas, controles ou prognósticos. Parte de práticas do cotidiano por conexões com o que tem vez nas relações do bebê com o mundo. $O$ ambiente deste bebê não é apenas uma interferência externa a ele, e que pode ou 
não colaborar para um bem sucedido resultado de desenvolvimento; o autor põe os processos relacionais - a mútua afetação - em evidência na construção da subjetividade. Este parece um modo de estudar o desenvolvimento que mais dialoga com o modo que escolhemos de produzir conhecimento - seguir sensivelmente os atores em suas práticas relacionais, ouvir suas narrativas e acompanhá-los na construção criativa de um singular modo de subjetivação. No entanto, Stern optou por um apelo direto às mães no título do livro, sugerindo maior relevância no papel delas como cuidadoras e responsáveis pelo desenvolvimento do bebê.

Costa (1989) traz importante contribuição ao apontar criticamente a centralidade da mãe na família e na nação no bojo do projeto higienista que emergiu com o saber e o poder médicos a partir do século XIX. Segundo o autor, a dócil adesão ao higienismo pode ser entendida pelo sentido de pertencimento à humanidade que a noção de naturalização dos processos humanos que a medicina instituiu. Se a família passava a representar um fragmento do 'grande todo' humanidade, a mulher foi recrutada, inclusive corporalmente, como a guardiã do tesouro: surge a força política da mãe, grande parceira do estado no controle dos processos de subjetivação através do desenvolvimento das crianças. Termos como indivíduo, segredo, intimidade ganham força, explicitando o paradoxo de pagar o alto custo de pertencer à humanidade e, simultaneamente, apartar-se dela.

Castro (1998) criticamente afirma que é preciso entender como cada sociedade dispõe de significados e representações sobre os momentos do ciclo vital humano; as mudanças sociais e as especificidades culturais têm papel fundamental no estudo da autora. Para ela, esta disciplina abarca a noção de 'evolução para o progresso' inserida no projeto da modernidade, assim como as noções de eficácia, controle racional, tecnologia, ciência, produção de verdades, capitalismo e competição. Segundo Castro (1998), a Psicologia do Desenvolvimento estabelece controle e previsão, classifica, marca as diferenças entre humanos de modo a estabelecer comparações normatizadoras e normalizadoras. Ela afirma que, somando-se isso a uma testagem psicométrica, temos visão científica e estatisticamente definida para a saúde, o que influiu na construção da Psicologia Clínica moderna, com terapeuta e cliente engessados na busca pela verdade através de métodos de mensuração e de ideais de saúde, aprendizagem e do modelo familiar burguês, tornando-se assim, ferramenta de tratamento de desvios. Assim, percebemos que o que é fluido, ambíguo, contraditório, caótico, intenso, fica de fora e é visto como patológico - a ser corrigido por técnicas terapêuticas, como ainda vemos acontecer na formação acadêmica do psicólogo. Jobim e Souza (2000), estudando os modos de produção de subjetividade no mundo atual, afirma que a marca da 
contemporaneidade é a ruptura do contato e do diálogo, inclusive das diversas áreas da própria Psicologia entre si. Para a autora, no mundo globalizado: "A diferença é hoje considerada um delito." (p.95). Isso nos remete a um campo de produção do conhecimento definido por separações rígidas, onde não se pode lidar com o diferir.

Ao colocarmos em diálogo as diferentes contribuições acima elencadas pretendemos promover um convite à reflexão crítica sobre o enfoque individualista e naturalizado ao desenvolvimento humano que muitos autores apresentam e, 0 quanto isso interfere nas formulações teóricas e no engendramento de práticas em Psicologia. A própria formação acadêmica traz a marca dessa construção de autonomia em oposição à heteronomia, pois o aluno ao cursar os períodos iniciais - teóricos - é posto em condição de dependência, enquanto que, ao passar à condição de estagiário, é subitamente lançado ao desenvolvimento de uma autonomia (ainda que supervisionada) para exercer os primórdios de sua inserção no mundo das práticas. Nesses momentos, entendemos a relevância de acompanharmos e partilharmos uma experiência feita tanto com a curiosidade, quanto com o sofrimento e com as hesitações deles, emoções que se incluem como material para a construção de uma rede: uma formação com o outro, que é em que consiste a própria feitura da formação ética. Recrutando autores como Vygotsky, por exemplo, que pensam o humano como permanente construção na relação com o outro, podemos estabelecer uma interlocução problematizadora acerca da condição processual e relacional do desenvolvimento humano, o que alcança a própria construção do psicólogo enquanto profissional para além do individualismo - seja particularizando-se em sua prática, seja na particularização ao olhar o outro. Quanto a isso, recorremos a Bock (2000), ao discorrer sobre a tendência que ela observa nos psicólogos de agir com autonomia e pró-autonomia dos sujeitos, a autora afirma que "Os psicólogos evidenciam, em seus discursos, principalmente quando relatam seus trabalhos, uma noção onipotente da profissão e de si próprios como profissionais, acreditando que têm em suas mãos a possibilidade de fazer do outro um homem feliz, de colocá-lo em movimento." (p. 23)

\section{Podemos produzir uma versão de práticas docentes e discentes em Psicologia do Desenvolvimento numa perspectiva que enlace a singularidade e o coletivo, que leve mais em conta o processual, a diversidade, o não-pronto, as sensações e as emoções que soam contraditórias?}

Recorremos a Despret (2011a) para problematizar a herança positivista nos textos e que se esparrama no ensino e no aprendizado de Psicologia do Desenvolvimento. Segundo a autora, ao herdarmos 
um problema, temos que lidar com esta herança, e buscar compreender como os fatos são postos em cena. Herdeiros não são necessariamente passivos no recebimento de suas heranças, pois têm condições de transformar o que recebem. Ao dar vez à multiplicidade de versões, voltam-se para o que vai ser criado, ampliado. Cada versão é antes de tudo, uma transformação criativa, uma criação que inspira temas diversos. De fato, a noção de 'versão' nos permite entender a multiplicidade de possibilidades, pois os novos sentidos que surgem têm a ver com quem ouviu, viu, leu e traduziu. A 'tradução' comporta a transformação, renovação, ou até mesmo revalidação de um tema - uma traição que tem o sentido de criação, libertação - pois é releitura onde quem a faz importa também. Consideramos tradução a produção de uma nova versão a partir de deslocamentos, descentramentos dos atores humanos e nãohumanos. Realidades vão sendo traduzidas, transladadas e transformadas a partir da entrada do pesquisador em campo, o que por si só já cria novas versões para a realidade. Este é um dos sentidos do 'fazer com' da TAR. A teoria não é reveladora, mas é o próprio campo que produz versões de si mesmo através de traduções - pelas movimentações dos atores e o registro das mesmas. A noção de tradução é incompatível com a Psicologia Moderna, se entendemos que os deslocamentos se articulam com a diversidade de possibilidades do campo. Despret (2011a) afirma que seguindo os atores em suas práticas, há abertura para multiplicarem-se as versões de como falar das emoções, sem qualificar o que é bom ou não, o que deve ou não entrar em um estudo. Este é um modo contemporâneo de produzir conhecimento: afastando-se de reducionismo explicativo que cria territórios intransponíveis em vez de abrir para o diálogo. Articulando a contribuição de Despret com nosso tema, pensamos que podemos colocar os textos em diálogo com as técnicas e práticas psicológicas que engendram, criando artesanalmente um percurso constituído pelas afetações que têm vez nas práticas em sala de aula. Não se trata de criar oposições ou hierarquias de importância dentre as contribuições dos diferentes autores em busca de novas verdades teóricas, o que seria 'reinventar a roda'. Problematizando a herança teórica e técnica que recebemos, podemos engendrar versões de desenvolvimento de práticas docentes e discentes.

As práticas em Psicologia que desejamos engendrar desde a sala de aula na graduação voltam-se para os processos de co-construção, cocriação. Quadros (2011) propõe: "... considerarmos a ideia do homem como um processo de transformações e imprevisibilidades e conectado a uma rede." Para a autora não há um mundo puramente cartesiano, "arrumado" em sequências ordenadas pela causalidade. Segundo ela, "... a ênfase está nas conexões, articulações, alianças, constituindo redes que produzem formas, relações, deslocamentos 
impermanentes." O conviver/desenvolver fica assim cada vez mais dificultado pela serialização, que individualiza, exclui, acarreta sofrimento, sintomas e desfigura a originalidade das práticas, as quais perdem o compromisso com o coletivo. Aqui, este é entendido enquanto construção compartilhada. Portanto, aqui propomos pensar a sala de aula na universidade como um lugar em que a problematização dos processos de desenvolvimento com/entre os estudantes ganhe relevância, em vez de apenas conduzir a disciplina apresentando-Ihes textos que estabelecem verdades com função instrumental embasadas na cientificidade positivista. Apontamos como possibilidade priorizar o desenvolvimento da perspectiva da produção ética desde a sala de aula como um fazer artesanal tecido entre professor e estudantes.

Observamos que há na modernidade todo um incentivo para que as capacidades físicas e psíquicas sejam aprimoradas a um nível de excelência condizente com as expectativas de progresso econômico, mesmo que ao custo de um brutal crescimento da alienação. A noção de laço social, compromisso com o bem estar do e no coletivo fica refém do conceito de individualidade exacerbada. Assistimos, portanto, ao declínio de práticas artesanais em todos os campos da ação humana, como vemos em Quadros (2011). As noções de criatividade e espontaneidade, tão ligadas à possibilidade de desenvolver-se, estão contemporaneamente a serviço de ideais de excelência pró produtividade econômica, inclusive nas práticas educacionais na academia, as quais preconizam a aquisição de instrumental técnico. Como vemos em Soares (2011):

...em nossa prática docente, nós nos deparamos com esse novo paradigma em subjetivação que aparece no empenho individualizado de adquirir o ofício de psicólogo pelo domínio de ferramentas básicas para o exercício futuro da profissão. Essa perspectiva indica a tendência ao afastamento da construção do papel de psicólogo por meio de uma formulação intersubjetiva, que propicia o desenvolvimento do coletivo. ( $p$. 81)

Aqui, nosso olhar segue na direção do criativo e do espontâneo que atenda a dimensão do 'existir com' no engendramento do desenvolvimento - este pensado também enquanto um dos fazeres na construção do psicólogo na universidade. O aprendizado para tornar-se psicólogo 'competente' acarreta alto custo: desconsiderarse enquanto um 'ser em relação com o outro'. Paradoxalmente, embora preparando-se individualmente para 'enfrentar' os desafios do mundo, o sujeito padece ao constatar o quanto está profundamente solitário para lidar com tais desafios. O sentido social e existencial das práticas vem sendo destruído pela perda da relação 
de mutualidade e de reciprocidade no que fazemos e em como afetamo-nos sensivelmente. De acordo com o que indicamos anteriormente, este processo tem vez na própria formação do aluno enquanto cursa a graduação em Psicologia. $E$, por que não pensarmos em uma articulação entre actantes na graduação em Psicologia que enseje a produção de conhecimento pelo pesquisar a partir das formulações éticas ali e então, e não só em adquirir conhecimentos para tornar-se psicólogo?

Na docência da graduação em Psicologia constantemente recebemos pedidos dos alunos por conhecer teorias e técnicas como ferramentas que deem conta de desafios éticos nos fazeres profissionais. Frequentemente indagam sobre o que é o certo e o que é errado na construção do desempenho profissional, tomando como referência a conduta prevista no Código de Ética Profissional do Psicólogo. As perguntas costumam trazer a noção de um psicólogo solitário e desamparado em sua atividade profissional, mirando o outro como objeto de intervenção. Não é raro surpreenderem-se com a multiplicidade de caminhos a serem adotados e dos muitos a serem construídos, em parceria com o outro e, especialmente no que diz respeito à relação com outros psicólogos. Na busca por dominar saberes, manejar ferramentas técnicas, produzir soluções e computar resultados, os estudantes demonstram querer repetir aquilo que é tido como pronto, testado e aprovado. A graduação em Psicologia parece fornecer a alunos e professores condições de alisamento, de higienização daquilo que provoca dobras, reentrâncias, sujeira - a dúvida, o não pronto. Assim, o político, o ético e o criativo ficam de fora, sendo eliminadas as diferenças que geram realidades, que seriam capazes de produzir novos mundos - a racionalidade da cultura do tecnicismo/especialismo sendo levada como o ideal da formação acadêmica do futuro psicólogo. Parece fazer parte do treinamento profissional substituir a singularidade dos alunos por faces maquiadas por certezas de cunho instrumental. A solidão dos sujeitos quando passarem a ser psicólogos constitui-se na grande ameaça, pois lidar com o inusitado torna-se o adversário temido, mas que precisa ser combatido com as ferramentas de dominação. Como se compartilha o sofrimento de aprender e de desaprender? Como tornar a formação do psicólogo uma prática de ética? Como se engendram práticas éticas sem levar em conta a relação com o outro? Problematizando as práticas do ensinar, propomos que 0 professor também desaprenda de ser o modelo incumbido da transmissão: transformando-se em dispositivo de mediação por surpreender-se com o mundo que co-construirá a cada dia na sala de aula ao atender as convocações para parceria com os alunos.

Sendo a TAR a proposta de Bruno Latour para outros olhares e fazeres ao que diz respeito aos agregados humanos, temos um outro modo de produzir conhecimento em ciências sociais, distanciando-se 
dos ditames da modernidade. (2012, p. 25). Latour provoca desarrumação no conceito 'social' enquanto situado no começo de tudo; para ele não é a sociedade que nos forma por não preexistir ao homem - ela é processualmente construída. Latour afirma que com o avanço tecnológico e científico, as noções de 'sociedade' e de 'relações sociais' foram fortemente afetadas e transformadas, deixando de haver um campo inteiramente neutro, puro, verdadeiro e separado a que se pudesse chamar de 'social' ou 'sociedade'. Para ele, sociedade seria: "... um dos muitos elementos de ligação que circulam por estreitos canais." (2012, p. 22). O autor aponta que na ciência social moderna os agregados sociais explicariam os fenômenos da Psicologia, da Economia, da Política, etc. Ele opta por seguir as associações econômicas, políticas, linguísticas, etc. que indicam os caminhos percorridos pelas agregações sociais. Latour (2012) afasta-se de focalizar categorias como classe social, gênero sexual, e prefere trabalhar na noção de rede, nas articulações, nas conexões, detectando e seguindo pequenos caminhos que se abrem e levam a combinar elementos heterogêneos, o que dá seu sentido de complexidade. Para ele, as práticas em rede são modos de subjetivação; na noção de rede entram humanos e não-humanos, pois tanto um quanto o outro têm história e constituem-se em plena mutualidade.

Problematizando o tema em foco em cada estudo - as narrativas interessamo-nos pelo o que se passa na rede de mútua afetação das práticas que têm vez num dado contexto, no caso, a sala de aula na graduação em Psicologia. Como todos são atores, então, não se trata de apenas descrever o que se passa, mas sim, de segui-los - bebês, crianças, adolescentes, adultos, idosos, novas configurações familiares, textos, sala de aula, novas tecnologias, etc. - e entender como as coisas são postas em cena. As informações provenientes de suas práticas nos permite encontrar novas conexões e, novas narrativas se abrem: como a vida acontece e como vai diferindo (Moraes, 2003b). Ao estudarmos o desenvolvimento dos actantes, tomamos consciência de nossa condição de actantes no processo, evidenciando simetria nas relações, colocando professor, alunos e os pesquisados como conexões produzidas e produtoras de sentido. Enfatizando mais os processos que os resultados, chegamos ao maior a partir do menor, dando ao que é da ordem do pessoal, dimensão política e, percebemos a possibilidade de um trabalho que se converte em etnográfico, ontológico, praxiográfico, compreensivo e, sobretudo, ético.

Seguindo essas afetações, pretendemos verificar como esta etapa da formação acadêmica do futuro psicólogo pode vir a consistir num processo de transformação através da desnaturalização de conceitos que os estudantes trazem de que tornar-se psicólogo consiste em dominar conhecimentos e técnicas que legitimem uma prática 
profissional normatizadora, posto que baseada na construção de uma versão fundada em saberes não marcados, verdades universais e em dualismos, como sujeito-objeto, indivíduo-sociedade, saudávelpatológico, interno-externo, instintivo-aprendido, etc. Podemos provocar o desaprender a ser aluno de Psicologia dentro de uma perspectiva da ciência positivista, assim como o desaprender a ser professor de alunos de Psicologia nesta mesma perspectiva, se isso significar não preconizar modelos ideais de práticas engessadas e pré-moldadas, convocando a produção ética como manejo/aprendizado técnico desde o grande laboratório de Psicologia do Desenvolvimento ético que a sala de aula pode se constituir.

Segundo Haraway (1995), o conhecimento é sempre situado, parcial, não generalizável e, qualquer normalidade não-marcada é inaceitável, pois o modo de conhecer vem de alguém e de algum lugar, então, talvez não se aplique a todos. Não há, segundo ela, 'o olhar', o olhar naturalizado; todo olhar é uma prótese, um modo de conhecer e de produzir conhecimento e, portanto, produz o próprio mundo. O modo de conhecer performa o mundo. A modernidade, ao produzir conhecimento desengajado, não-marcado, produz um mundo de ninguém para ninguém: é o que ela chama de 'olhar de Deus' - saber absoluto, totalizante, dado a priori, higienizado, invisível, sem as marcas dos processos que tiveram vez no campo, indicado por ela como o olhar do 'homem branco europeu'. Haraway propõe que o 'olho' se mostre, evidenciando sua mediação, já que para ela não há 'olho' isento de marcação - ao produzirmos conhecimento, precisamos indicar de que lugar estamos falando.

Com a TAR falamos sempre a partir de conexões parciais, nãocategorizantes; o universal pode ser um ponto de chegada, mas não de partida. Conexões parciais contém e contam estórias específicas que ora se conectam com outras e, ora não. Entendendo então que narrativas são parciais, estudar Psicologia do Desenvolvimento consiste em tornar o conhecimento situado visível, subvertendo o discurso da normalização e da normatização; evitamos assim o conhecimento não-situado, não-marcado, que não fala de ninguém. Importamo-nos mais com as cadeias de construção, com as concatenações, com as conexões entre os atores, com os fluxos, com o 'entre'; importamo-nos principalmente, portanto, com tudo que engendra processos, do que com resultados ou conclusões. Nosso desafio em estudar/discutir o Desenvolvimento Humano é o de rastrear estas conexões perguntando que práticas levam a determinadas construções, seguindo o invisível e o que faz funcionar - sendo estes os modos de subjetivação que nos interessam, já na sala de aula da graduação. Nossa busca refere-se o que é imperceptível, o sutil, o que pode parecer insignificante nas trocas e que opera a diferença nessa mútua e criativa construção de novos mundos. Como actantes nesse processo, podemos agir de modo a 
suscitar perguntas interessantes mutuamente - as que possam produzir movimentos que interessem aos actantes e que dão vez a novas versões. A pergunta interessante não tem nada de ideal, mas é a que possibilita o aparecimento de vários caminhos - o 'seguir adiante' - e, 'cria mundos'. É o 'devir com', que poderá dar vez a uma saber marcado, produzido relacional e processualmente no campo. Como dito anteriormente, a isso chamamos de 'translação': transformar-se no encontro com o outro, o que torna o ensinar/aprender também um pesquisar e, uma política ontológica.

\section{Como isso pode se dar nas práticas na graduação em Psicologia na contemporaneidade?}

Um dos caminhos é o de surpreender-se e deixar-se surpreender ao estudar/aprender/pesquisar, deixando-se conduzir pelo que a ciência da modernidade chamaria de 'desvios' e excluiria; incluir o que parece atrapalhar os propósitos do estudo, os processos - onde a vida cumpre o 'diferir'. Melhor é problematizar o que parece ser ou criar problemas, ou parece ser natural, ou ainda, banal. No cotidiano da docência convivemos com inquietações (nossas e dos alunos) que não estão previstas como conteúdo do trabalho pedagógico e, no entanto, entendemos que não podem ser varridas do cenário acadêmico a pretexto de serem inconvenientes, irrelevantes e/ou nocivas. Nestes 'desvios' pode estar a fertilidade das interações entre actantes na universidade: é aí, no encontro entre seres encarnados que o ético emerge. Segundo C. Geertz (2001), em ciências sociais o que é geral/universal é falso; a orientação para o previsível exclui possibilidades. Segundo o autor, 'mente humana' e 'natureza humana' são conceitos que ganharam força por oposição ao relativismo cultural, o que enfraqueceu a noção de diversidade cultural, dando vez a uma tendência essencialista e universalizante ao se pensar o humano em suas relações no mundo. Para ele, não há uma origem ou estrutura prévia que dê conta de formatar a humanidade e suas relações. Pensamos, a partir de Geertz, que a ênfase em categorizações, em generalizações, em classificações, presentes nos ditames dos desenvolvimentos teóricos/pedagógicos/médicos/psicológicos/jurídicos/midiáticos que tomaram as produções de conhecimento, engendram práticas higienistas, universalistas e pacificadoras das ansiedades apontadas pelo relativismo em ciências sociais. Entendemos que o mesmo ocorre com a Psicologia do Desenvolvimento em sua versão moderna, criando referências generalizantes para futuras práticas profissionais. Ao nos lançarmos na docência pela perspectiva da TAR, por outro lado, o universal pode até ser um ponto de chegada, mas não de partida para qualquer estudo. 
De acordo com Law e Urry (2004), o mundo não é estável, a modernidade é que tenta estabilizá-lo excluindo o que desestabiliza; podemos tentar desarrumar as estabilizações, pois reconhece que nelas há algo que pulsa, que é desorganizado e provoca metamorfoses. Segundo os autores, para entender as mudanças do mundo é preciso acompanhá-las, seguindo-as. A partir do rastreamento de trajetórias, evidencia-se a alternância entre permanência e transformação. Assim, podemos estudar a partir de narrativas que oferecem casos específicos, mostram incoerências, indicam caminhos de práticas que estão sendo encenadas e que, portanto, produzem sentidos. Pensamos o sujeito como ativamente conectado a redes e vínculos, inclusive com não humanos na contemporaneidade - tempo de forte presença da tecnologia na regulação dos modos de existência e coexistência.

Para Arendt (2008), na TAR evitamos explicações e o engessamento de linhas rigidamente objetivas, agregamos maleabilidade aos estudos que, por sua complexidade, exigem abertura: "Se uma coisa suporta muitos pontos de vista é justamente porque é altamente complexa, intrincada, bem organizada, 'objetivamente bela'. Não se trata de relativismo, mas de relatividade." (p.8)

Como o diálogo entre os diversos campos do conhecimento favorece a ampliação das perspectivas no estudo do desenvolvimento, agregamos agora as palavras de Merleau Ponty (2006): “Não há meio para explicar o desenvolvimento físico pelo desenvolvimento psíquico ou vice-versa... Não existe desenvolvimento do tipo finalista, governado pela consciência, assim como não há desenvolvimento causal, teoria puramente corporal do desenvolvimento." (p. 503). Mais adiante, encontramos: "Portanto, o desenvolvimento, assim como não é destino, também não é liberdade incondicional." (p. 504). O autor revela sua disposição por adotar uma posição dialética no estudo do desenvolvimento humano, afastando-se da dicotomia entre posições mecanicistas/sensacionistas (na qual prepondera a interferência do meio sobre o sujeito) por um lado, e idealistas/intelectualistas (defendem que atos do intelecto vêm e rompem radicalmente com a estrutura anterior) por outro lado. Merleau-Ponty indica que o desenvolvimento só pode ser pensado como permanente transformação, movimento que modifica o próprio movimento, de modo que a quantidade de mudanças dá vez à qualidade, em plena reciprocidade "entre o dentro e o fora". (p.245)

Pensamos neste texto como uma primeira contribuição para um olhar às práticas acadêmicas - ao lecionar e aprender - a partir de um enfoque a Psicologia do Desenvolvimento: tudo que está 'sendo feito' pelos actantes pode e deve ser incluído como prática em rede e entre redes produzindo sentidos singulares. Entendemos que os estudantes podem, em problematizações coletivas e, dentro e fora da sala de aula, produzir, e não só receber um conteúdo pronto produzido por 
outros, sobre outros. Desta maneira, estaremos fazendo a diferença em relação ao pensamento positivista que ainda impregna a graduação em Psicologia, o qual, ao considerar o homem como essência, de natureza biológica, o recorta de sua condição política, recortando igualmente a Psicologia de suas muitas ligações com outros campos do saber. Este é um modo possível de ampliar as práticas em sala de aula na graduação em Psicologia na direção de construir conhecimento pela ressignificação de conteúdos através de práticas que articulem ética à aplicabilidade técnica dos referidos conhecimentos.

Retornamos a Moraes (2003a), quando a autora indica que: "A vida tolera a diferença. Viver não é mais do que diferir." (p.62). Segundo ela, importam menos os universais, mas o que faz mudar. A abertura à pluralidade dos fazeres e dos olhares interconectados compõe um estudo multidisciplinar que contempla mais amplamente o que podemos pretender com uma outra prática que coloque professor e alunos numa construção a partir do diálogo com autores que problematizem as produções consideradas como reveladoras de verdades universalizantes.

A discussão orientada pela reflexão acerca de variados temas produz descentramento no conteúdo programático, que desloca-se do discurso dominante em desenvolvimento para o esforço de articular o texto pronto com as novas narrativas que ali se produzem. A sala de aula, os quadros (negro e, atualmente branco), o datashow, os textos, alunos, professor, figuram como actantes de um processo dialógico que é posto em cena pela própria condição de diferir, pela incerteza, pela não previsibilidade, enfim, por tudo o que as escalas de desenvolvimento e as tabelas de habilidades não são capazes de encenar e de explicar. Fora dos muros da universidade humanos e não humanos convivem, interagem, encontram-se, diferem, inventam e reinventam-se, engendram realidades oferecendo-nos narrativas que, ao serem coletadas, produzem um conhecimento situado. Interessa-nos, portanto, despertar no aluno a atitude do pesquisador: aquele que participa da construção de um conhecimento que não é só da ordem do cognitivo ou só do social, coletando narrativas provenientes de percursos pessoais e coletivos - conhecimento marcado - articulando-as com o material teórico.

Law (2008) interessa-se por uma atitude em ciência que não se limite a descrever, mas que também encene realidades - uma metodologia performativa. Law e Mol (1995) indicam que as práticas que produzem conhecimento são as que criam um conhecimento que funcione, que gere realidades. Law e Mol (2002) propõem que, em vez de 'por em ordem' podemos criar ordens, ordenações, lógicas, estilos, repertórios, discursos, os quais dissolvem as dicotomias, inclusive entre o 'simples' e o 'complexo'. 
Frota (2007) corrobora esta reflexão: "Vivendo numa condição pósmoderna, precisamos entender o conhecimento e os diversos saberes de uma perspectiva que requer de cada um de nós que abandonemos a "grande narrativa" de uma unidade teórica de conhecimento e nos contentemos com objetivos mais locais e práticos." (p.154). Complementando a noção de conhecimento como processualidade, construção compartilhada por atores conectados em redes, trazemos mais uma vez a contribuição de Frota (2007):

A compreensão da impossibilidade de se tomarem as grandes narrativas como verdades cristalizadas, a certeza da multiplicidade de vivências e de seus significados que se ancoram nas também múltiplas historicidades, a aceitação da parcialidade das verdades, são elementos que não podem ser deixados de lado. Desse modo, os saberes são construídos de modo tímido, sabendo-se incompletos, precários e parciais. Contudo, ao mesmo tempo, mais verdadeiros. (p.158)

\section{Considerações finais}

As práticas da ciência psicológica positivista produzem 0 'conhecimento não-marcado' - não falam de ninguém e não se aplicam a ninguém, mas padronizam todos num modelo ideal de desenvolvimento, existência e produtividade, cuja ênfase está no individualismo, no racionalismo, nos resultados, na competitividade e no desempenho. Então, Estado, família, medicina, psicologia e pedagogia aliaram-se na produção de práticas de controle das individualidades. Revisitamos esta herança que desemboca nas práticas na graduação em Psicologia, e propusemos iniciar uma reflexão/desarrumação pela TAR, já que esta constitui-se num método que se propõe a favorecer a criação de novas sensibilidades. Discutimos a contribuição de autores de diferentes linhas de pensamento tentando estabelecer um diálogo com a TAR, de modo a iniciar um debate que instigue a reinvenção da Psicologia do Desenvolvimento como campo de estudo e como disciplina que possa engajar-se ética e politicamente na formação do psicólogo. Se entendemos que o conhecimento interessante é o que traz novas versões, então, ao estudarmos/praticarmos Psicologia do Desenvolvimento podemos fazer emergir novas versões de conhecimento performadas por professores e alunos na graduação em Psicologia. A contribuição da TAR pode agregar às práticas na disciplina Psicologia do Desenvolvimento a visão de integração entre permanência e transformação, sem torná-la relativista, mas sim, uma versão relacional e processual de produção de conhecimento desde a rede da sala de aula na universidade, conforme apontamos no 
decorrer do texto. Isso inclui indicar uma perspectiva de abertura do curso de Psicologia, ao colocar professores e alunos como actantes em práticas de produção de conhecimentos acompanhando outros actantes em suas práticas cotidianas contemporâneas de produção de sentido, sem regular as singularidades por gênero, classe social, faixa etária, etc. Propomos para o termo 'desenvolvimento' um sentido mais amplo: o desenvolvimento de uma interlocução com outros saberes, como Antropologia, Filosofia, Sociologia, Artes, Neurociência, Educação, etc., de modo a afirmar uma permanente e não apaziguadora problematização para o que se referir ao tema do 'ser com o mundo'. Deste modo, podemos pensar em apontar para a produção em Psicologia na graduação o caminho de reinventar-se como campo do fazer provocação à reflexão e o convite à interlocução e, que seguindo sua errância, venha a constituir-se num campo de abertura a mais possibilidades de conexões em redes e menos engessamento em definições - uma versão política, portanto, para os fazeres em Psicologia desde as práticas na academia. Assim, somos instigados e instigamos a pensar a partir das redes, a não linearidade do desenvolvimento: o existir humano em conexão com não humanos.

Em nossa experiência, como docente desta disciplina, temos constatado a circulação de afetações a partir das discussões motivadas pelos textos, os quais vêm com a missão de instigar a desacomodação, o deslocamento de posições engessadas e engessadoras acerca da ética dos fazeres em Psicologia do Desenvolvimento. Entendemos que a rede de mútua afetação que se monta entre professor e alunos em sala de aula já se constitui uma prática em Psicologia, na qual se pode eticamente vivenciar a relação com o outro: professor e colegas. Nossa participação nesse processo suscita o interesse em pesquisar/lecionar para dar vez a versões de práticas acadêmicas pelo viés da produção de ética a partir das discussões em sala de aula, uma vez que consideramos a possibilidade de redistribuir as afetações que nos fazem agir nas práticas em Psicologia, como vemos em Moraes (2011, p. 178). Em não havendo uma única versão possível - uma versão hegemônica de práticas em Psicologia, acreditamos que podemos então performar outras realidades - versões de fazeres éticos em psicologia - desde as discussões com os alunos em sala de aula. $\mathrm{Na}$ condição de docente/pesquisador, participamos não apenas como observadores dos atores, colhendo movimentos interessantes a nosso propósito de pesquisadores; somos também atores, somos parte do campo.

A noção de articulação entre atores humanos e não humanos - novos leitores, antigos textos, tecnologia - joga nova luz às possibilidades de construção de um conhecimento que não exclua o erro, o desvio, a sensação de desamparo diante das incertezas: uma maneira de dar vez a novos sentidos. A diferença, os novos olhares e fazeres nos 
estudos do Desenvolvimento Humano, podem articular novos nexos e engendrar instabilidades, ao deslocarem-se das margens dos processos psicológicos inscritos na modernidade para transformaremse em conexão entre redes de afetações: o 'não-marcado' dando vez ao 'marcado', 'situado', já que em TAR falamos do pequeno para o grande. Por tratar-se de uma metodologia performativa, pretendemos assim, contribuir para repovoar a sala de aula da graduação em Psicologia de seres encarnados, sujeitos que partilham a dor e a delícia do aprender e desaprender - sejam eles tanto professores quanto alunos.

Reafirmamos que propomos estudar o desenvolvimento a partir da complexa rede de conexões, para além da centralidade no papel da mãe como responsável mor, o que abarca outros atores, inclusive os não humanos, e múltiplos fazeres que produzem como efeito múltiplas versões de desenvolvimento. Portanto, pretendemos ir para além dos determinismos nas construções em torno deste tema.

Se desejamos incluir o desenvolvimento de reflexões, revelações e desenvolturas, os actantes do estudo estarão implicados, envolvidos em suas idas e voltas, volvendo e revolvendo o que está dado e o que pode ser criado. Para além dos especialismos - em que a ciência vem se disseminando - que produzem fragmentações, apostamos nas articulações entre os fragmentos que produzem agenciamentos. Tomando consciência de sua conexão com a rede de produção de sentidos, os estudantes passarão de somente testemunhas a fazedores de versões de Psicologia do Desenvolvimento conhecimento situado. De fato, nos parece que isso representa propor uma desacomodação no cenário das práticas na universidade e nas produções de conhecimento em Psicologia, na direção de fazeres e lugares politicamente encarnados para futuros psicólogos.

\section{Referências}

Arendt, R. J. J. (2008). Maneiras de pesquisar no cotidiano: contribuição da Teoria do Ator-Rede. Revista Psicologia \& Sociedade, 20, Edição Especial, 7-11. Recuperado em 13 de maio, 2014, de http://www.scielo.br/psoc

Bock, A. M. B. (2000). As influências do Barão de Münchhausen na Psicologia da Educação. In E. Tanamachi, M. Proença, \& M. Rocha (Orgs.). Psicologia e Educação: desafios teórico-práticos. pp. 11-33. São Paulo: Casa do Psicólogo.

Carmichael, L. (1964). Manual de Psicología Infantil. Barcelona: Librería El Ateneo Editorial.

Castro, L. R. (1998). Infância e Adolescência Na Cultura do Consumo. RJ: Nau. 
Castro,L. R. (2013). O futuro da infância e outros escritos. Rio de Janeiro: 7 Letras.

Costa, J. F. (1989). Ordem médica e norma familiar. Rio de Janeiro: Edições Graal Ltda.

Despret, V. (2011a). Les Faiseuses d'histoires. Que font les femmes à la penseé? Paris: Éditions de la Découverte.

Despret, V. (2011b). Leitura etnopsicológica do segredo. (C. Marconi, Trad.). Dossiê Despret. Revista Fractal de Psicologia, 23(1), 528. Recuperado em 13 de maio, 2014, de http://www.uff.br/periodicoshumanas/index.php/Fractal/article/ view/646/494.

Frota, A. M. M. C. (2007). Diferentes concepções da infância e adolescência: a importância da historicidade para sua construção. Revista Estudos e Pesquisas em Psicologia, 7(1), 147-160. Recuperado em 31 de maio, 2014, de http://www.epublicacoes.uerj.br/index.php/revispsi/article/view/10956/8669

Geertz, C. (2001). Nova luz sobre a Antropologia. (V. Ribeiro, Trad.). Rio de Janeiro: J orge Zahar Editor.

Gerrig, R., \& Zimbardo, P. (2005). A Psicologia e a Vida. (16a ed.). (R. C. Costa, Trad.). Porto Alegre: Artmed.

Haraway, D. (1995). Saberes localizados: a questão da ciência para o feminismo e o privilégio da perspectiva parcial. Cadernos Pagu, 5, 07-41.

Heckert, A. L. C., Corona, C. R., Manzini, J. M., Machado, R. E. B. e Fardin, V. L. (2001) A escola como espaço de invenção. pp. 239-250. In: Clio-Psyché hoje - Fazeres e dizeres psi na história do Brasil. Rio de Janeiro: Relume Dumará.

Jobim e Souza, S. (2000). Subjetividade em questão - a infância como crítica da cultura. Rio de Janeiro: 7 Letras.

La Taille, Y. de, Oliveira, M. K. de, \& Dantas, H. (1992). Piaget, Vygotsky, Wallon. Teorias Psicogenéticas em Discussão. São Paulo: Summus Editorial.

Latour, B. (2012). Reagregando o Social - uma introdução à teoria do Ator-Rede. (G. C. C. Sousa, Trad.). Salvador/Bauru: EDUFBA/EDUSC.

Law, J., \& Mol, A. (1995). Notes on materiality and sociality. Heterogeneities.net [on line], Recuperado em 10 de maio de 2014,

http://www. heterogeneities.net/publications/LawMol1995Materi alityAndSociality.pdf

Law, J., \& Mol, A. (2002). Complexities: an introduction. In J. Law, \& A. Mol (Eds.). Complexities: social studies of knowledge practices. (1-22). USA: Duke University Press.

Law, J. (2008). Seeing like a survey. Heterogeneities. net [on line]. Recuperado em 13 de maio, 2014, de 
http://www. heterogeneities.net/publications/Law2008SeeingLik eASurvey.pdf

Law, J., \& Urry, J. (2004). Enacting the social. Heterogeneities.net. [on line]. Recuperado em 13 de maio, 2014, de http://www. heterogeneities. net/publications/LawUrry2005Enact ingTheSocial.pdf

Mattos, A. (2012). Liberdade, um problema do nosso tempo - os sentidos de liberdade para os jovens no contemporâneo. Rio de Janeiro: Editora FGV.

Merleau-Ponty, M. (2006). Psicologia e Pedagogia da Criança. (I. C. Benedetti, Trad.). São Paulo: Martins Fontes.

Moraes, M. (2003a) O que é a Psicologia? Revista de Psicologia da UnC, 1(2), pp. 69-73.

Moraes, M. (2003b) A Psicologia como reflexão sobre as práticas humanas: da adaptação à errância. Journal: Estudos de Psicologia, 8(3), 535-539.

Moraes, M. (2001). A Psicologia, uma ciência? Revista Paradoxa, IV(9), 55-64.

Moraes, M. (2011). Pesquisar: verbo ou substantivo? Narrativas de ver e não ver. Pesquisas e práticas psicossociais, 6(2), 174-181.

Oliveira, M. K. (1992) O problema da afetividade em Vygotsky. pp. 75-84. In: La Taille, Y. de, Oliveira, M. K. de, Dantas, H. Piaget, Vygotsky, Wallon. Teorias Psicogenéticas em Discussão. São Paulo: Summus Editorial.

Papalia, D., Olds, S. W., \& Feldman, R. D. (2006). Desenvolvimento Humano. ( $8^{\mathrm{a}}$ ed.). (D. Bueno, Trad.). Porto Alegre: Artmed.

Pikunas, J. (1979). Desenvolvimento Humano. (A. B. Simões). São Paulo: Mc Graw-Hill do Brasil.

Pombo, C. (2013). A Mãe e o tempo: ensaio da maternidade transitória. Rio de Janeiro: Memória Visual.

Quadros, L. C. T. (2011). A prática clínica individual como desdobramento e reverberação do coletivo. Revista IGT na Rede, 8(14), 56-66. Recuperado em 13 de maio, 2014, de http://www.igt.psc.br/ojs/

Soares, L. L. M. (2011). Ética e dialogicidade na formação do psicólogo. Revista Psicologia Ensino \& Formação, 2(1), 77-93. Recuperado em 21 de maio, 2014, de http://pepsic. bvsalud.org/scielo.php?script=sci_issuetoc\&pid=2 $177006120110001 \& \operatorname{lng}=$ pt\&nrm $=$ iso

Stern, D. (1991). Diário de um bebê - o que seu filho vê, sente e vivencia. (D. Batista, Trad.). Porto Alegre: Artmed.

\section{Endereço para correspondência}

Luciana Loyola Madeira Soares

Universidade do Estado do Rio de Janeiro

Programa de Pós Graduação em Psicologia Social 
Rua São Francisco Xavier, 524 10 andar sala 10.009 bloco F, Maracanã, CEP 20550-013, Rio de Janeiro - RJ, Brasil

Endereço eletrônico: psi.lucianasoares@gmail.com

Recebido em: 03/06/2014

Reformulado em: 20/09/2014

Aceito para publicação em: 23/09/2014

\section{Notas}

* Professora da graduação em Psicologia do Instituto Brasileiro de Medicina de Reabilitação - RJ, RJ, Brasil. Supervisora de estágio em Psicologia Clínica da graduação em Psicologia do Centro Universitário Celso Lisboa - RJ, RJ, Brasil. Membro do Laboratório gestáltico UERJ - Configurações e Práticas Contemporâneas, RJ, RJ, Brasil. Doutoranda - PPGPS UERJ, RJ, RJ, Brasil. Mestre - Universidade Veiga de Almeida, RJ, RJ, Brasil. Especialista em Psicologia Clínica e Educacional Conselho Regional de Psicologia 05, RJ, RJ, Brasil. Especialista em Saúde Mental Infanto Juvenil - Pontifícia Universidade Católica, RJ, RJ, Brasil. 